\title{
Tailoring swelling of alginate-gelatin hydrogel microspheres by crosslinking with calcium chloride combined with transglutaminase
}

\author{
Nadezhda Pilipenko ${ }^{\mathrm{a}, \mathrm{b}}$, Odinei Hess Gonçalves ${ }^{\mathrm{a}, \mathrm{b}, \mathrm{c}}$, Evandro Bona ${ }^{\mathrm{c}}$, Isabel P. Fernandes ${ }^{\mathrm{a}, \mathrm{b}}$, \\ João A. Pinto ${ }^{\mathrm{a}, \mathrm{b}}$, Guilherme D. Sorita ${ }^{\mathrm{a}, \mathrm{b}, \mathrm{c}}$, Fernanda Vitória Leimann ${ }^{\mathrm{a}, \mathrm{b}, \mathrm{c}, * *}$, \\ Maria Filomena Barreiro ${ }^{\mathrm{a}, \mathrm{b}, *}$ \\ ${ }^{a}$ Centro de Investigação de Montanha (CIMO), Instituto Politécnico de Bragança, Campus de Santa Apolónia, 5300-253, Bragança, Portugal \\ ${ }^{\mathrm{b}}$ Laboratory of Separation and Reaction Engineering - Laboratory of Catalysis and Materials (LSRE-LCM), Polytechnic Institute of Bragança, Campus Santa Apolónia, \\ 5301-253, Bragança, Portugal \\ ${ }^{\mathrm{c}}$ Programa de Pós-Graduação em Tecnologia de Alimentos (PPGTA), Universidade Tecnológica Federal do Paraná, Campus Campo Mourão (UTFPR-CM), via Rosalina \\ Maria Dos Santos, 1233, CEP 87301-899, Caixa Postal: 271, Campo Mourão, Paraná, Brazil
}

\section{A R T I C L E I N F O}

\section{Keywords:}

Alginate

Gelatin

Ionic crosslinking

Enzymatic-induced crosslinking

Hydrogel microspheres

Swelling

\begin{abstract}
A B S T R A C T
Alginate-based hydrogels can find uses in a wide range of applications, including in the encapsulation field. This type of hydrogels is usually ionically crosslinked using calcium sources giving rise to products with limited internal crosslinking. In this work, it is hypothesized that the combination of alginate crosslinked by calcium chloride (external crosslinking; ionic mechanism) with gelatin crosslinked by transglutaminase (internal crosslinking; enzymatic induced mechanism) can be used to tailor the swelling behavior of alginate-based hydrogel microspheres. A systematic study was conducted by covering process variables such as gelatin content, TGase concentration, and $\mathrm{CaCl}_{2}$ contact time, added by statistic tools as central composite rotatable design (CCRD), principal component analysis (PCA) and multiobjective optimization, to map their effect on the resulting water content after production (expressed as swelling ratio), and swelling properties at pH 3 and 7. Among the studied variables, particle's swelling was mostly affected by the gelatin content and transglutaminase concentration.
\end{abstract}

\section{Introduction}

Alginate-based hydrogels are widely used in commercial products as wound dressings (Aspen Medical Europe, 2016; Caló \& Khutoryanskiy, 2015), and as encapsulating and stabilizing agents for food formulations (Food Ingredients Brasil, 2010; Food Ingredients Brasil, 2013). However, they can present constraints to their application, namely high permeability to water-soluble compounds in encapsulation processes (İnal, Işıklan, \& Yiğitoğlu, 2017), fact related with the lack of an effective internal crosslinking. Also, problems related with their susceptibility to disintegration in the presence of an excess of monovalent ions or $\mathrm{Ca}^{2+}$ chelating agents, and contact with harsh chemical environments, have been reported (Lopes, Bueno, Júnior, de, \& Finkler, 2017; Mokarram, Mortazavi, Najafi, \& Shahidi, 2009). These disadvantages can be prevented by blending alginate with other polymers (İnal et al., 2017).
Different biopolymers were investigated to combine with alginate, namely methoxyl pectin, and $\kappa$-carrageenan to produce hybrid hydrogel microspheres (Gonçalves et al., 2016), and chitosan to produce alginate-chitosan microspheres (Guo et al., 2017). In both studies, the productive method comprised an emulsification step followed by crosslinking. Alternatively, İnal et al. (2017) used the dripping method to produce $\mathrm{pH}$-sensitive alginate-g-poly( $\mathrm{N}$-vinyl-2-pyrrolidone)/gelatin beads with glutaraldehyde as the chemical crosslinker. They concluded that the swelling ratio of the beads increased due to the presence of gelatin, a biopolymer with high swellability and hydrophilicity. Nevertheless, the use of glutaraldehyde limits their applications since it is considered a toxic compound (Ha, Nam, Khang, \& Park, 2017).

Kawaguti, Carvalho, Figueira, \& Sato (2011) applied the enzyme transglutaminase (TGase) as crosslinker for gelatin, and $\mathrm{CaCl}_{2}$ for alginate, to immobilize Erwinia sp. D12 cells in alginate-gelatin microparticles. TGase catalyzes the acyl-transfer reaction between the

\footnotetext{
* Corresponding authors at: Centro de Investigação de Montanha (CIMO), Instituto Politécnico de Bragança, Campus de Santa Apolónia, 5300-253, Bragança, Portugal.

** Corresponding authors at: Programa de Pós-Graduação em Tecnologia de Alimentos (PPGTA), Universidade Tecnológica Federal do Paraná, Campus Campo Mourão (UTFPR-CM), via Rosalina Maria Dos Santos, 1233, CEP 87301-899, Caixa Postal: 271, Campo Mourão, Paraná, Brazil.

E-mail addresses: fernandaleimann@utfpr.edu.br (F.V. Leimann), barreiro@ipb.pt (M.F. Barreiro).
} 
carboxyamide group of the peptide bound to the glutamine residues (acyl donors) and a variety of primary amines (acyl acceptors), including the amino groups of lysine residues in certain proteins (Santhi, Kalaikannan, Malairaj, \& Arun Prabhu, 2017). It is largely applied at industrial level to improve the characteristics of meat-based foodstuff (water-binding, purge loss, and cooking loss), as well as gelation and emulsion stability in some other products (Gharibzahedi et al., 2018). In the work of Kawaguti et al. (2011) the authors did not evaluate the swelling properties as a function of the used synthesis conditions, and a fixed and excessive crosslinking time was used ( $12 \mathrm{~h})$. In another study, Roy, Bajpai, and Bajpai (2009) encapsulated the pesticide endosulfan in alginate-gelatin based microspheres without gelatin crosslinking, and by fixing alginate crosslinking time with $\mathrm{CaCl}_{2}$ as $48 \mathrm{~h}$. The effect of using a gelatin coating in alginate beads was studied by Lopes et al. (2017). In this case, the crosslinking time with $\mathrm{CaCl}_{2}$, used to harden the microparticles, was $30 \mathrm{~min}$, considerably inferior to the conditions applied by Roy et al. (2009) and Kawaguti et al. (2011).

The influence of $\mathrm{CaCl}_{2}$ crosslinking time was addressed by Németh et al. (2018) by studying the encapsulation of paraffin with alginate. The range of studied crosslinking times (1-13 min) had a significant impact on paraffin encapsulation. Lotfipour, Mirzaeei, \& Maghsoodi (2012) also evaluated the hardening time (15 and $60 \mathrm{~min}$ ) of alginate on the encapsulation of Lactobacillus acidophilus concluding that the hardening time has a significant effect on the evaluated responses (encapsulation efficiency, cell viability and particle size).

The aim of this study was to prepare microspheres by combining alginate with gelatin using the dripping technique. This strategy will enable a fast-external crosslinking (alginate crosslinking with $\mathrm{CaCl}_{2}$ ), important to promptly define the initial shape of the microspheres, and an internal crosslinking assured by the gelatin counterpart (crosslinking with transglutaminase), in order to avoid an easy disruption of the microspheres and control swelling behavior. Moreover, the interest of combining different statistical tools to systematize the analysis of the obtained results, will be highlighted.

Microspheres were obtained under different experimental conditions (gelatin content, TGase concentration, and $\mathrm{CaCl}_{2}$ contact time), defined using a central composite rotatable design (CCRD) to get insights into their water content after production (expressed as swelling ratio, i.e. dry-basis), and swelling behavior at $\mathrm{pH} 3$ and $\mathrm{pH} 7$ (response variables). The interaction between the response variables was analysed by PCA and related with the synthesis conditions. Moreover, multiobjective optimization was further used to determine the experimental conditions leading to the simultaneous maximization or simultaneous minimization of the responses, and the obtained samples under these conditions characterized by DSC and FTIR to get some insights into the crosslinking processes. The developments presented in this work can find application in various industrial fields, among them the food sector.

\section{Materials and methods}

\subsection{Standards and reagents}

Sodium alginate ( $\geq 99 \%$ purity), from Brown algae, and viscosity of 4-12 cP $\left(1 \%\right.$ in $\left.\mathrm{H} 2 \mathrm{O}, 25^{\circ} \mathrm{C}\right)$ was acquired from Fluka Chemika (Germany). Gelatin from porcine skin, Type A, gel strength 78-80 g Bloom (average molecular weight 20,000-25,000), was acquired from Sigma Life Science (Germany). Transglutaminase (TGase, ACTIVA WM 110 active units/g) was kindly gifted by Ajinomoto Foods Europe S.A.S. (France). Calcium chloride dihydrate powder ACS and citric acid anhydrous ACS were obtained from Panreac Quimica (Spain), tri-Sodium Citrate 2-hydrate ACS grade was obtained from Panreac AppliChem (Germany). Potassium bromide FT-IR grade, were provided by Fluka Chemie (Germany). Water was treated in a Milli-Q water purification system (TGI Pure Water Systems, Greenville, SC, USA).
Table 1

Coded levels (real values in parentheses) for the experimental design (gelatin content $\left(\mathrm{X}_{1}, \% \mathrm{wt}\right)$, TGase concentration $\left(\mathrm{X}_{2}, \mathrm{U} / \mathrm{g}\right)$ and $\mathrm{CaCl}_{2}$ contact time $\left(\mathrm{X}_{3}\right.$, $\min )$ ).

\begin{tabular}{llll}
\hline \multirow{2}{*}{ Run } & \multicolumn{2}{l}{ Coded levels (real values) } \\
\cline { 2 - 4 } & $\mathrm{X}_{1}(\%)$ & $\mathrm{X}_{2}(\mathrm{U} / \mathrm{g})$ & $\mathrm{X}_{3}(\mathrm{~min})$ \\
\hline 1 & $-1(25)$ & $-1(10)$ & $-1(21)$ \\
2 & $-1(25)$ & $-1(10)$ & $1(81)$ \\
3 & $-1(25)$ & $1(30)$ & $-1(21)$ \\
4 & $-1(25)$ & $1(30)$ & $1(81)$ \\
5 & $1(75)$ & $-1(10)$ & $-1(21)$ \\
6 & $1(75)$ & $-1(10)$ & $1(81)$ \\
7 & $1(75)$ & $1(30)$ & $-1(21)$ \\
8 & $1(75)$ & $1(30)$ & $1(81)$ \\
9 & $-1.68(7.95)$ & $0(20)$ & $0(51)$ \\
10 & $1.68(92.04)$ & $0(20)$ & $0(51)$ \\
11 & $0(50)$ & $-1.68(3.18)$ & $0(51)$ \\
12 & $0(50)$ & $1.68(36.81)$ & $-1.68(0.55)$ \\
13 & $0(50)$ & $0(20)$ & $1.68(101.45)$ \\
14 & $0(50)$ & $0(20)$ & $0(51)$ \\
15 & $0(50)$ & $0(20)$ & $0(51)$ \\
16 & $0(50)$ & $0(20)$ & \\
\hline
\end{tabular}

\subsection{Microspheres preparation}

For the preparation of the microspheres, gelatin was dissolved in distilled water $(25 \mathrm{ml})$ at $50^{\circ} \mathrm{C}$ under continuous stirring during $30 \mathrm{~min}$. After, sodium alginate was added to the gelatin solution and maintained under constant magnetic stirring during $60 \mathrm{~min}$. TGase was subsequently added under continuous stirring $(350 \mathrm{rpm})$ at room temperature for $10 \mathrm{~min}$. Microspheres were produced by dropping the obtained mixture directly to a calcium chloride aqueous solution $(500 \mathrm{ml}$, $2.65 \% \mathrm{wt}$ ) with the aid of a peristatic pump (Ismatec, Kinesis inc., Illinois, USA) at a flow rate of $0.5 \mathrm{ml} / \mathrm{min}$. Contact time of the droplets with calcium chloride was set as determined by the experimental design (section 2.3). After this, the system was heated to $50{ }^{\circ} \mathrm{C}$ and TGase was allowed to react for $15 \mathrm{~min}$ under constant magnetic stirring. Finally, the microparticles suspension was vacuum filtered to recover the beads that were weighed and then freeze-dried.

\subsection{Experimental design}

A central composite rotatable design (CCRD) was applied to define the conditions used to obtain the microspheres (Table 1). The evaluated experimental parameters were gelatin content in the polymeric mixture (gelatin plus alginate), to be abbreviated as gelatin content $\left(\mathrm{X}_{1}, \% \mathrm{wt}\right)$, transglutaminase concentration expressed as active units relative to gelatin, to be abbreviated as TGase concentration $\left(\mathrm{X}_{2}, \mathrm{U} / \mathrm{g}\right)$, and contact time of the droplets with calcium chloride solution, to be abbreviated as $\mathrm{CaCl}_{2}$ contact time $\left(\mathrm{X}_{3}, \mathrm{~min}\right)$. The responses were defined as the water content after production (expressed as swelling ratio, i.e. dry-basis) $\left(\mathrm{Y}_{1}\right.$, $\% \mathrm{wt})$, and swelling degree (SD) at $\mathrm{pH} 3\left(\mathrm{Y}_{2}, \% \mathrm{wt}\right)$ and $\mathrm{pH} 7\left(\mathrm{Y}_{3}, \% \mathrm{wt}\right)$. The experimental factors were chosen based on preliminary results reported by the research group (Simoni et al., 2017), while pH 3 and 7 were chosen due to the suitability for food applications, since a large number of products present $\mathrm{pH}$ values in the range 3-7. Examples included condensed milk ( $\mathrm{pH}$ 6.59), fresh milk (UHT-processed) $(\mathrm{pH}$ 6.09), mayonnaise ( $\mathrm{pH} 3.46$ ), pineapple jam (pH 3.02) (Gabriel, 2008). Data were analysed using the software Statistica 7.1 (StatSoft Incorporation, Tulsa). TGase reaction time was kept constant (15 min).

The significance of the individual effects was assessed by ANOVA ( $95 \%$ confidence interval), in order to adjust the experimental models to the evaluated responses. Then the overall fit of the model containing the significant coefficients was evaluated by the coefficient of determination $\left(R^{2}\right)$, the adjusted coefficient of determination $\left(R_{a d j}^{2}\right)$, ANOVA (95\% confidence interval), the analysis of partition of the 
residual sum of squares in pure error, and the lack of fit. Contour plots were obtained for the validated models and for the evaluated responses by keeping constant the third independent variable at the central point. A second-order polynomial expression was adjusted for each dependent variable (responses), as described in Eq. (1), where $b_{0}$ is the intercept; $b_{1}, b_{2}$ and $b_{3}$ are the regression coefficients for linear effects; $b_{11}, b_{22}$ and $b_{33}$ are the regression coefficients for the quadratic effects; $b_{12}, b_{13}$ and $b_{23}$ are the regression coefficients for the interaction effects; and $x_{1}$, $\mathrm{x}_{2}$ and $\mathrm{x}_{3}$ are the codified values for independent variables.

$\mathrm{y}=\mathrm{b}_{0}+\mathrm{b}_{1} \mathrm{x}_{1}+\mathrm{b}_{2} \mathrm{x}_{2}+\mathrm{b}_{3} \mathrm{x}_{3}+\mathrm{b}_{11} \mathrm{x}_{1}{ }^{2}+\mathrm{b}_{22} \mathrm{x}_{2}{ }^{2}+\mathrm{b}_{33} \mathrm{x}_{3}{ }^{2}+\mathrm{b}_{12} \mathrm{x}_{1} \mathrm{x}_{2}+$

$b_{13} x_{1} x_{3}+b_{23} x_{2} x_{3}$

\subsection{Principal component analysis}

To understand the relationship between the obtained responses, principal component analysis (PCA) was applied using MATLAB R2008b (MathWorks Inc., Natick, MA). The results obtained for water content $\left(\mathrm{Y}_{1}\right)$, SD at $\mathrm{pH} 3\left(\mathrm{Y}_{2}\right)$ and $\mathrm{SD}$ at $\mathrm{pH} 7\left(\mathrm{Y}_{3}\right)$ were placed in columns and the experimental runs in rows. Before analysis, each column was mean centered and divided by its variance, resulting in a scaled matrix.

\subsection{Sequential simplex optimization}

The optimization objective was to obtain the experimental conditions to simultaneously minimize the response variables (MPmin), and the ones to simultaneously maximize the response variables (MPmax). This means that under MPmin the responses (water content and swelling degree at $\mathrm{pH} 3$ and 7) are at their minimum values and that at MPmax they are at their maximum values. To carry out the multiobjective optimization, the models obtained from experimental design $\left(\mathrm{Y}_{1}, \mathrm{Y}_{2}\right.$ and $\left.\mathrm{Y}_{3}\right)$ were combined to form a global response using desirability functions (Fuchs, Ribeiro, Bona, \& Matsushita, 2013). This approach involved the transformation of each estimated response variable $Y_{i}$ to a desirability value $d_{i}$, where $0 \leq d_{i} \leq 1$ and $d=1$ represents a desirable value and $\mathrm{d}=0$ an undesirable value. In this transformation, it is also possible to assign a relative importance for each dependent variable (Castro, Silva, Tirapegui, Borsato, \& Bona, 2003). The individual desirabilities $\left(\mathrm{d}_{\mathrm{i}}\right)$ were then combined using a geometric mean to form the overall desirability (D). This single value of $\mathrm{D}[0,1]$ gives the overall assessment of the desirability of the combined response levels, and D will increase as the balance of the properties becomes more favourable. Then the simplex algorithm (Bona, Borsato, Sérgio dos Santos Ferreira, \& Paula Herrera, 2000; Gao \& Han, 2012) was executed to found combinations of the independent variables $\left(\mathrm{X}_{1}, \mathrm{X}_{2}\right.$ and $\left.\mathrm{X}_{3}\right)$ that maximize D. After the convergence of the value of $\mathrm{D}$, the optimized conditions for $X_{1}, X_{2}$ and $X_{3}$ were then applied in a validation experiment. The observed values for $Y_{1}, Y_{2}$ and $Y_{3}$ in the validation experiment was compared with the predicted values for the optimized conditions. The multiobjective optimization was performed using scripts developed by the authors in Matlab R2008b.

\subsection{Microspheres characterization}

The produced microspheres were characterized concerning water content, swelling degree (SD) at $\mathrm{pH} 3$ and at $\mathrm{pH}$ 7, which were used as response variables $\left(\mathrm{Y}_{1}, \mathrm{Y}_{2}\right.$ and $\mathrm{Y}_{3}$, respectively) in the performed experimental design. Moreover, swelled microspheres (i.e. microspheres after $24 \mathrm{~h}$ under swelling) were observed by optical microscopy (OM).

The water content $\left(\mathrm{Y}_{1}\right)$ was determined according to Eq. (2), where, $\mathrm{W}_{1}$ is the weight $(\mathrm{g})$ of wet particles and $\mathrm{W}_{2}$ the weight $(\mathrm{g})$ of dry (lyophilized) particles. Water content translates the swelling ratio of the microspheres right after production.
Water content $(\%)=\frac{W_{1}-W_{2}}{W_{2}} \times 100$

To access SD at pH $3\left(\mathrm{Y}_{2}\right)$ and $\mathrm{SD}$ at $\mathrm{pH} 7\left(\mathrm{Y}_{3}\right)$, lyophilized particles were incubated in water at the defined $\mathrm{pH}$, at $23^{\circ} \mathrm{C}$ during $24 \mathrm{~h}$. SD was calculated by using Eq. (3) where $\mathrm{W}_{S}$ and $\mathrm{W}_{\mathrm{D}}$ are the weight $(\mathrm{g})$ of the swollen and dry particles, respectively.

$S D(\%)=\frac{W_{S}-W_{D}}{W_{D}} \times 100$

FTIR spectra were obtained in a MB300 (ABB, Zurich, Switzerland) apparatus in transmittance mode using 32 scans. min $^{-1}$ with a resolution of $4 \mathrm{~cm}^{-1}$ and a scanning range of $4000-550 \mathrm{~cm}^{-1}$. Spectra were obtained with Horizon MB software version 3.4 and normalized. Samples were grinded, finely dispersed into $\mathrm{KBr}$ and pelletized before analysis. Thermal characterization of the produced particles was carried out by DSC (Netzsch DSC 204 F1 Phoenix). Samples (5-10 mg) were packed in closed aluminium holders and subjected to heating from $-80^{\circ} \mathrm{C}$ to $250{ }^{\circ} \mathrm{C}$ at a heat flow rate of $10^{\circ} \mathrm{C}$. $\mathrm{min}^{-1}$ under nitrogen flux of $50 \mathrm{~mL} \cdot \mathrm{min}^{-1}$. All samples were grinded and placed in a vacuum oven at $400 \mathrm{mmHg}$ and $50{ }^{\circ} \mathrm{C}$ for $24 \mathrm{~h}$ before analysis. Microspheres morphology was accessed under 40x magnification using an optical microscope Nikon H600 L (Tokyo, Japan) with a digital camera (DS-Fi3, 5.9 megapixel), a CMOS image sensor, and Nikon Image System Software acquire and analyse the data. Fourier Transform Infrared spectroscopy (FTIR) and Differential Scanning Calorimetry (DSC) characterization was applied to microspheres produced under the determined optimized conditions.

\section{Results and discussion}

\subsection{Experimental design}

The experimental results for the three evaluated responses (water content, $\mathrm{SD}$ at $\mathrm{pH} 3$ and $7, \mathrm{Y}_{1}, \mathrm{Y}_{2}$ and $\mathrm{Y}_{3}$, respectively) are presented in Table 2. The observed versus predicted values are presented in Fig. 1 and data in Table 3 summarize the ANOVA results obtained for the defined responses. In Table 4 the coefficients of the obtained models are presented and contour plots are presented in Fig. 2.

A satisfactory agreement between the observed and predicted values was found for the models representing the water content and SD at $\mathrm{pH}$ 7 , with a random distribution of the points within the complete experimental range, as can be observed in Fig. 1. The distribution of the points for the model representing SD at $\mathrm{pH} 3$ presents a non-random distribution along the tested experimental range, with points more concentrated in a specific range (low SD region). All models presented a

\section{Table 2}

Obtained responses (water content $\left(\mathrm{Y}_{1}, \% \mathrm{wt}\right), \mathrm{SD}$ at $\mathrm{pH} 3\left(\mathrm{Y}_{2}, \% \mathrm{wt}\right)$ and $\mathrm{SD}$ at $\left.\mathrm{pH} 7\left(\mathrm{Y}_{3}, \% \mathrm{wt}\right)\right)$, according to the experimental design.

\begin{tabular}{llll}
\hline \multirow{2}{*}{ Run } & \multicolumn{3}{l}{ Responses } \\
\cline { 2 - 4 } & $\mathrm{Y}_{1}(\% \mathrm{wt})$ & $\mathrm{Y}_{2}(\% \mathrm{wt})$ & $\mathrm{Y}_{3}(\% \mathrm{wt})$ \\
\hline 1 & 1317.30 & 294.52 & 305.64 \\
2 & 1269.42 & 339.48 & 315.31 \\
3 & 1209.43 & 194.79 & 165.76 \\
4 & 1226.00 & 189.45 & 168.60 \\
5 & 1763.74 & 341.08 & 328.56 \\
6 & 1942.24 & 621.16 & 644.37 \\
7 & 1679.31 & 667.38 & 448.67 \\
8 & 1659.81 & 428.72 & 430.34 \\
9 & 1139.32 & 257.79 & 210.37 \\
11 & 1467.38 & 244.18 & 213.91 \\
12 & 1411.99 & 251.23 & 230.59 \\
13 & 1597.78 & 254.48 & 235.14 \\
14 & 1352.50 & 288.94 & 274.23 \\
15 & 1430.15 & 256.04 & 246.28 \\
16 & 1445.95 & 261.40 & 253.50 \\
\hline
\end{tabular}




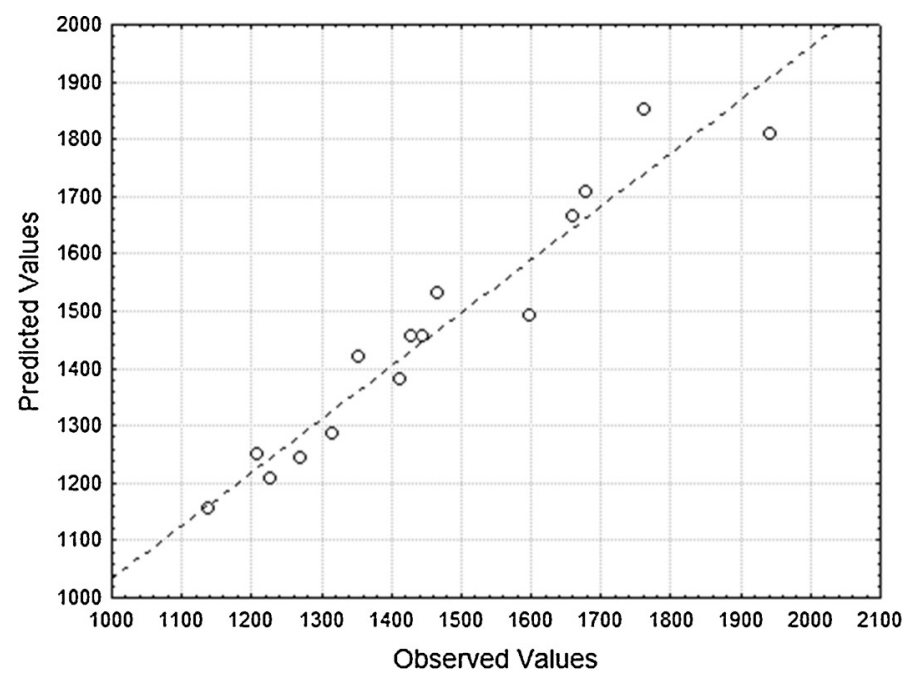

(a)

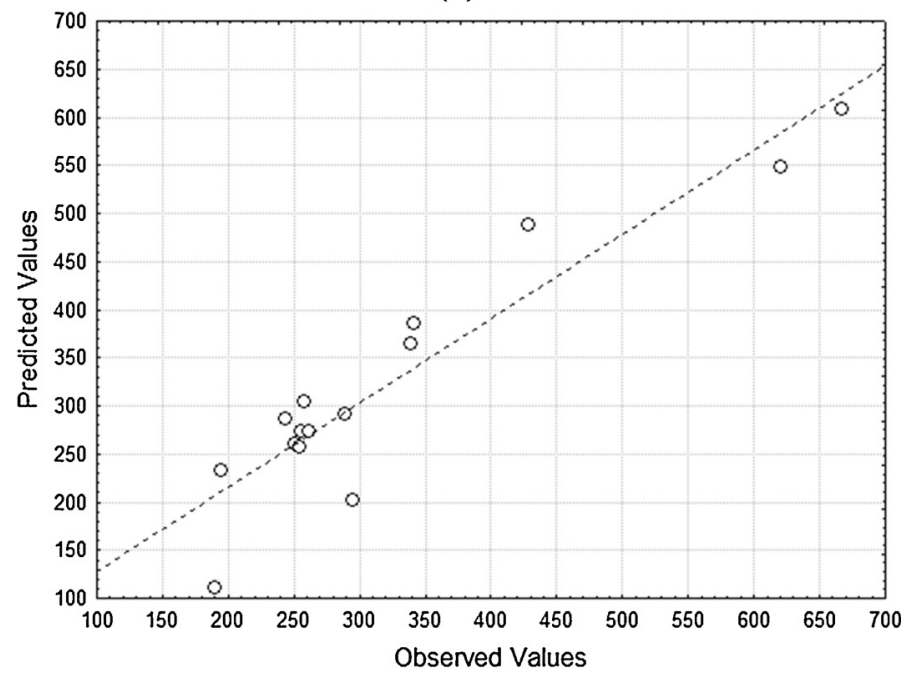

(b)

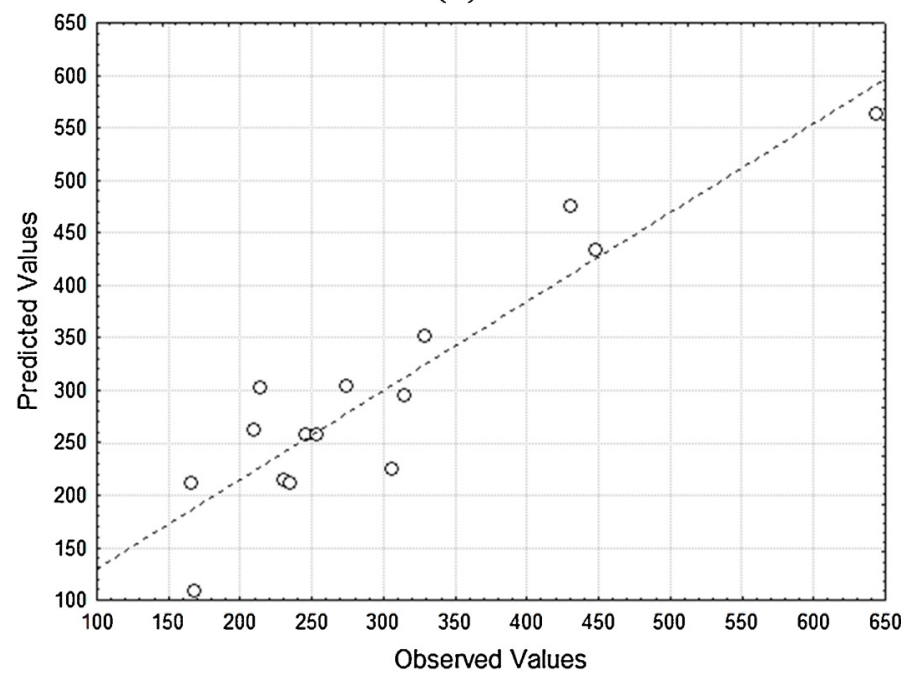

(c)

Fig. 1. Predicted versus observed values for experimental models of: (a) Water content ( $\left.\mathrm{Y}_{1}, \% \mathrm{wt}\right)$; (b) $\mathrm{SD}$ at $\mathrm{pH} 3\left(\mathrm{Y}_{2}, \% \mathrm{wt}\right)$; and (c) SD at pH 7 ( $\left.\mathrm{Y}_{3}, \% \mathrm{wt}\right)$. 
Table 3

ANOVA analysis for the experimental models describing water content (\%wt), $\mathrm{SD}$ at $\mathrm{pH} 3(\% \mathrm{wt})$ and SD at $\mathrm{pH} 7$ (\%wt).

\begin{tabular}{clllll}
\hline Model & & Sum of square & DF & Mean square & p-value \\
\hline Water content (\% & Regression & 671887.70 & 5 & 134377.54 & 0.000067 \\
wt) $\mathrm{R}^{2}=92.81$ & Error & 51978.00 & 9 & 5775.33 & - \\
$\mathrm{R}_{\text {adj }}^{2}=88.83$ & Lack of fit & 51853.00 & 8 & 6481.62 & 0.107016 \\
& Pure error & 125.00 & 1 & 125.00 & - \\
& Total SS & 723865.70 & 14 & - & - \\
$\mathrm{SD} \mathrm{pH} \mathrm{3} \mathrm{( \% wt)}$ & Regression & 248582.70 & 6 & 41430.45 & 0.002933 \\
$\mathrm{R}^{2}=87.54$ & Error & 35386.20 & 8 & 4423.28 & - \\
$\mathrm{R}_{\text {adj }}^{2}=78.19$ & Lack of fit & 35371.80 & 7 & 5053.11 & 0.041082 \\
& Pure error & 14.40 & 1 & 14.40 & - \\
& Total SS & 283968.90 & 14 & - & - \\
$\mathrm{SD} \mathrm{pH} \mathrm{7} \mathrm{( \% wt)}$ & Regression & 190151.70 & 7 & 27164.53 & 0.018562 \\
$\mathrm{R}^{2}=84.82$ & Error & 34022.80 & 7 & 4860.40 & \\
$\mathrm{R}_{\mathrm{adj}}^{2}=69.65$ & Lack of fit & 33996.70 & 6 & 5666.12 & 0.051906 \\
& Pure error & 26.10 & 1 & 26.10 & - \\
& Total SS & 224174.50 & 14 & - & - \\
\hline
\end{tabular}

Table 4

Regression coefficients of the fitted models for: water content (\%wt) and SD at pH 7 (\%wt).

\begin{tabular}{lllll}
\hline Coefficients & Water content (\%wt) & p-value & SD pH 7 (\%wt) & p-value \\
\hline$b_{0}$ & 1456.078 & 0.002 & 285.05 & 0.005 \\
$b_{1}$ & 256.396 & 0.009 & 122.95 & 0.009 \\
$b_{1}{ }^{2}$ & 46.398 & 0.058 & 74.56 & 0.016 \\
$b_{2}$ & -44.761 & 0.043 & -25.80 & 0.034 \\
$b_{2}{ }^{2}$ & - & - & - & - \\
$b_{3}$ & -20.857 & 0.091 & 27.51 & 0.032 \\
$b_{3}{ }^{2}$ & - & - & - & - \\
$b_{1} b_{2}$ & -26.946 & 0.092 & 24.08 & 0.048 \\
$b_{1} b_{3}$ & - & - & 35.62 & 0.032 \\
$b_{2} b_{3}$ & - & - & -42.62 & 0.027 \\
\hline
\end{tabular}

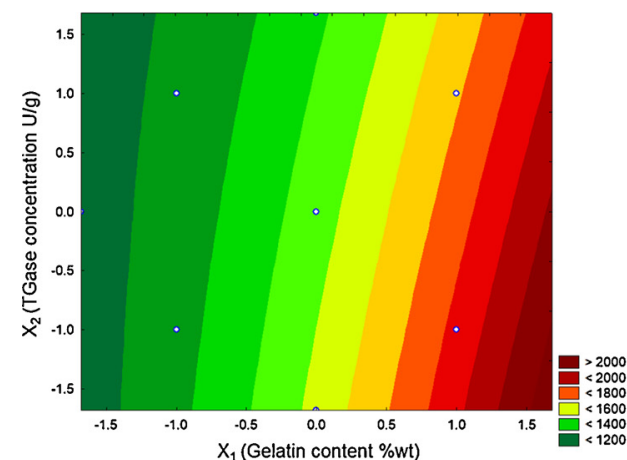

(a)

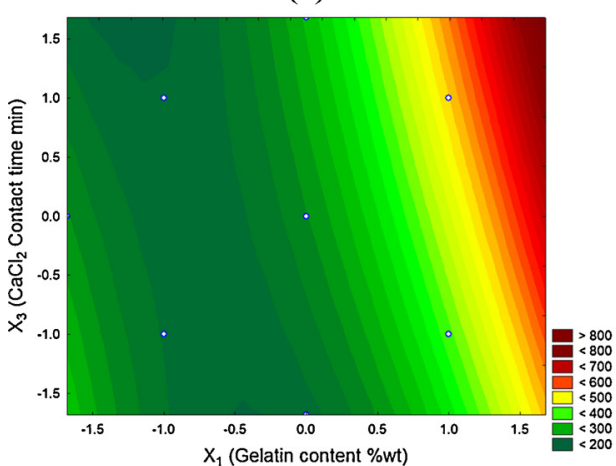

(c) significant $\mathrm{p}$-value $(\mathrm{p}<0.05)$ for the regression coefficient, however the model representing the swelling degree at $\mathrm{pH} 3$ presented a significant lack of fit $(\mathrm{p}<0.05)$. The correlation coefficients $\left(\mathrm{R}^{2}\right.$ and $\left.\mathrm{R}_{\mathrm{adj}}^{2}\right)$ indicated a good fit to the experimental data and that most of the response variability was explained by the models. These findings indicate that the three models may be used for prediction within the evaluated experimental range, with exception of the swelling degree at $\mathrm{pH} 3$.

Analyzing the results presented in Table 4, it is possible to conclude that gelatin content $\left(b_{1}\right)$, and TGase concentration $\left(b_{2}\right)$ were the only variables significantly affecting $(\mathrm{p}<0.05)$ the water content, i.e. the water retained into the polymeric matrix just after microspheres production. The interaction between the gelatin content and TGase concentration $\left(b_{1} b_{2}\right)$ was kept in the model to increase its prediction ability. It can be observed from the analysis of Fig. 2(a) that, at constant TGase concentration, the water content increases with gelatin content increase. At a constant gelatin content and as TGase concentration increases until the central point (50\% of gelatin), a non-significant increase is observed. After this point, water content remained constant. This is an indicative that at low gelatin content, water content behavior is defined by the alginate component, thus independent of the TGase concentration, being the water retained into the particles similar.

In Fig. 2(b), the response SD at $\mathrm{pH} 7$ is presented showing the interaction between the gelatin content and the TGase concentration. It can be observed that higher swelling degrees were obtained when higher gelatin contents were used, independent of the TGase concentration. Also, a curvature with a minimum region located in the range above the central point of TGase concentration and below the central point of the gelatin content was observed. This behavior indicates that at this $\mathrm{pH}$ value, lower swelling degrees are obtained when alginate is the predominant compound of the polymeric mixture, as well as when transglutaminase concentration is high. It is known that a higher concentration of transglutaminase promotes a higher crosslinking, leading to a lower swelling degree (Jin \& Zhong, 2013).

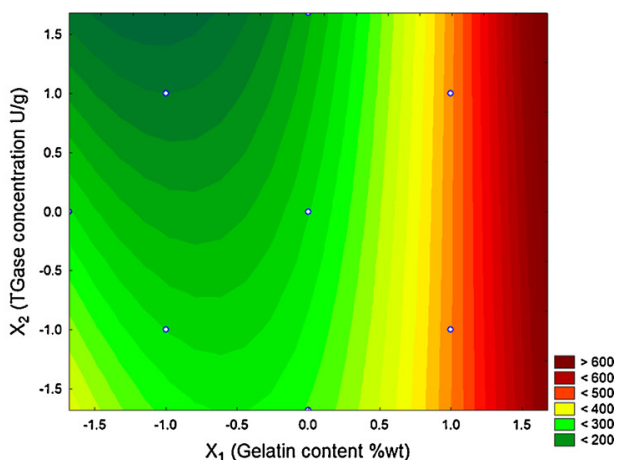

(b)

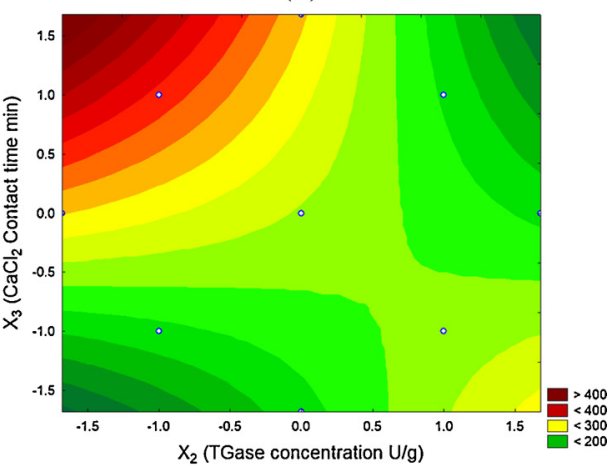

(d)

Fig. 2. Contour plots for the obtained model's significant factors, centered in the central point of the third variable: (a) Water content ( $\mathrm{X}_{1}$ versus $\mathrm{X}_{2}$ ); (b) $\mathrm{SD}$ at $\mathrm{pH} 7$ ( $\mathrm{X}_{1}$ versus $\left.\mathrm{X}_{2}\right)$; (c) $\mathrm{SD}$ at $\mathrm{pH} 7\left(\mathrm{X}_{1}\right.$ versus $\left.\mathrm{X}_{3}\right)$; (d) $\mathrm{SD}$ at $\mathrm{pH} 7\left(\mathrm{X}_{2}\right.$ versus $\left.\mathrm{X}_{3}\right)$. 


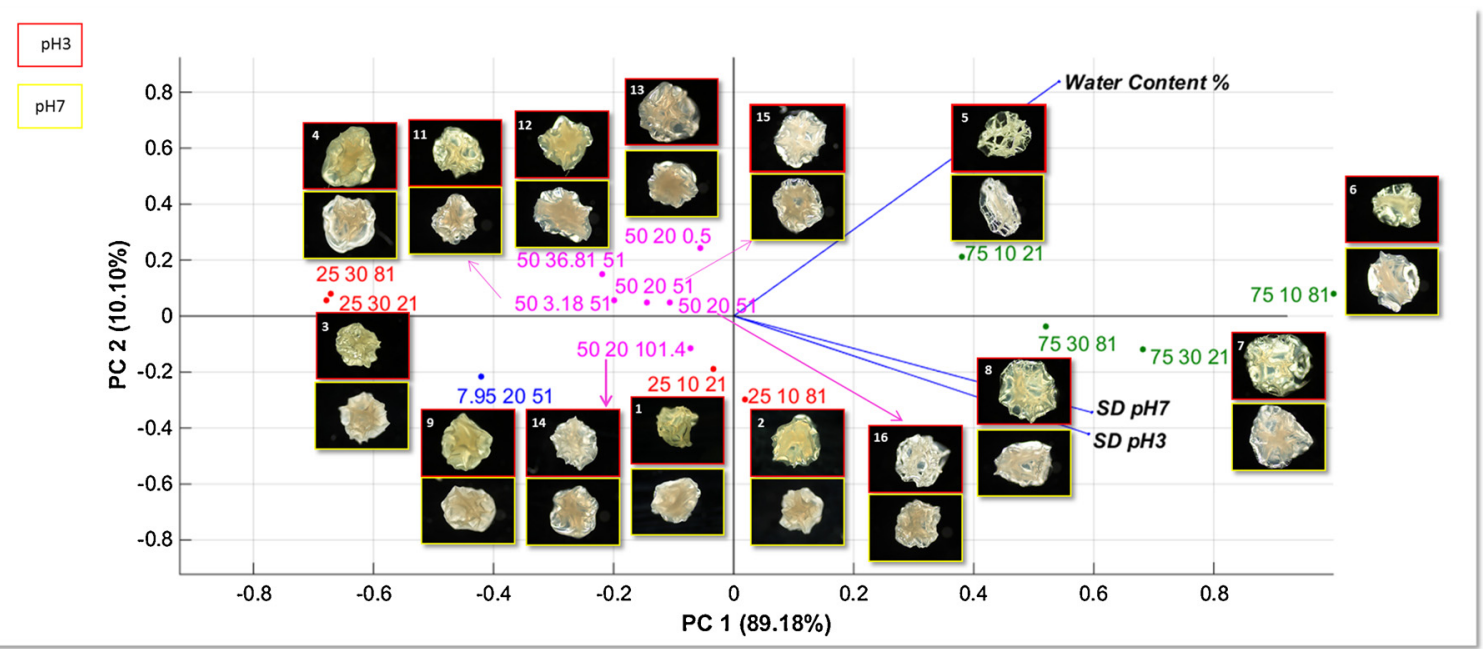

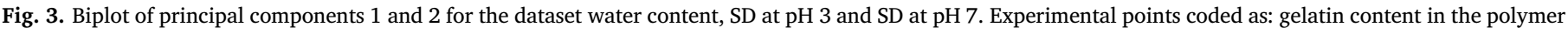

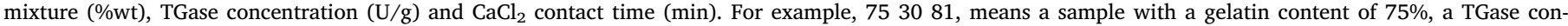

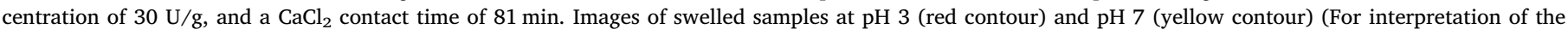
references to colour in this figure legend, the reader is referred to the web version of this article).

\subsection{Principal component analysis}

A PCA involving the three responses (water content, SD at $\mathrm{pH} 3$ and SD at 7) was evaluated in order to identify trends and outliers, as well as uncover relationships among observations and variables and among the variables themselves (Boeing et al., 2014). The biplot obtained for the two identified principal components ( $99.28 \%$ of explained variance) is presented in Fig. 3. Microscopy images of the swelled microparticles at $\mathrm{pH} 3$ (marked in red) and at $\mathrm{pH} 7$ (marked in yellow) were also included.

Particles presented spherical shape after production and an approximate size of $3000 \mu \mathrm{m}$, becoming of irregular shape after freeze drying, characteristic that was maintained after $24 \mathrm{~h}$ under swelling.

Samples were separated in three cluster regions according to their gelatin content. Samples produced with the highest gelatin content (75\%) (green dots) were grouped together presenting the highest water content, and SD at pH 3 and 7. The microspheres produced using $75 \%$ of gelatin, $10 \mathrm{U} / \mathrm{g}$ of TGase, and a $\mathrm{CaCl}_{2}$ contact time of $21 \mathrm{~min}$ (75 10 21 sample), presented morphological characteristics that differ from the other ones using the same gelatin content, by showing a more translucent alveolar-like structure. The sample with the closest composition is the 751081 , where the higher contact time (81 min instead of 21) resulted in an opaquer structure, fact compatible with a higher crosslinking degree of the alginate. Appositively, when TGase concentration was $30 \mathrm{U} / \mathrm{g}$ (samples 753021 and 7530 81) the same contact time difference did not impact particle's morphology.

Samples produced with a gelatin content of $50 \%$ are clustered in the center of the projection space together with two samples produced with $25 \%$ of gelatin (samples 251021 and 2510 81), meaning that they have similar characteristics. They show an opaquer structure, in comparison with samples with a gelatin content of $75 \%$. The samples with $25 \%$ of gelatin and a TGase concentration of $30 \mathrm{U} / \mathrm{g}$, located in a different region of the projection space, presented the lowest swelling degrees at pH 3 and 7 (Table 2).

For a TGase concentration lower than $10 \mathrm{U} / \mathrm{g}$, differences in the microstructure were found as a function of the $\mathrm{CaCl}_{2}$ contact time, independently of the used gelatin content. Particles produced using lower contact times presented a more translucent aspect, becoming opaquer for higher contact times. This means that a TGase concentration of 10 $\mathrm{U} / \mathrm{g}$ was not enough to promote extensive gelatin crosslinking, even at low concentrations, being the final morphology dependent on alginate crosslinking extension.
The presence of high amounts of alginate favored the spherical-like structure. Moreover, for $\mathrm{pH} 7$, if alginate predominates, the external surface become smoother, fact associated with the higher swelling capability of this polymer at $\mathrm{pH}$ 7. On contrary, at $\mathrm{pH} \mathrm{3}$, and due to alginate $\mathrm{pH}$ responsive swelling behavior, samples presented a shrinking pattern as it is expected for pHs below pH 5 (George \& Abraham, 2007). The pKa of alginic acid (uronic acid residues carboxyl groups) ranges between 3.4 and 4.4, depending on the alginate type and presence of salts. Therefore, when the tested $\mathrm{pH}$ was 3 , alginate was below the pKa values, resulting in the protonation of the acid groups. Since the carboxylate groups of alginate are protonized the electrostatic repulsion among them is lowered and shrinkage is favored (Pasparakis \& Bouropoulos, 2006). The only sample produced with a gelatin content of $7.95 \%$ is positioned between the cluster produced with $25 \%$ of gelatin and $30 \mathrm{U} / \mathrm{g}$ of TGase, and the cluster produced with $50 \%$ of gelatin. This sample is, among all the produced samples, the one presenting the lowest water content, but a swelling degree, both at $\mathrm{pH} 3$ and 7 , very similar to the one obtained for samples produced with a gelatin content of $50 \%$. Swelling degree presented opposed behavior at $\mathrm{pH} 3$ and 7 due to the isoelectric point of the gelatin and its influence on the established interactions between polymer chains and water (Voron'ko, Derkach, Kuchina, \& Sokolan, 2016).

It is possible to conclude that samples with similar water content and swelling behavior at $\mathrm{pH} 3$ and 7 can be obtained by using a gelatin content of $50 \%$, any of the tested TGase concentrations, and contact times within the studied experimental range. Also, if a content of gelatin of $25 \%$ is preferred, the same behavior must be expected by using a TGase concentration of $10 \mathrm{U} / \mathrm{g}$.

\subsection{Optimization of the experimental conditions and validation}

To optimize the obtained responses, the maximization and the minimization of the three evaluated responses were considered. In Table 5 the optimized conditions $\left(\mathrm{MP}_{\min }\right.$ and $\left.\mathrm{MP}_{\max }\right)$, as well as the validation of the obtained results, are presented. The microspheres produced under the validated conditions were then characterized by FTIR and DSC and the results are presented in Figs. 4 and 5, respectively. Endothermic peaks and the respective enthalpy values are also included in the thermograms of Fig. 5. Enthalpies for samples $\mathrm{MP}_{\text {min }}$ and $\mathrm{MP}_{\max }$ were calculated considering the gelatin concentration of each sample.

With the exception of the response swelling degree at $\mathrm{pH} 3$ for 
Table 5

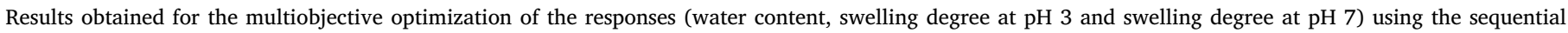
simplex method (the used relative importance of the dependent variables was $11-1$ ).

\begin{tabular}{|c|c|c|c|}
\hline & & $\mathrm{MP}_{\min }$ & $\mathrm{MP}_{\max }$ \\
\hline \multicolumn{4}{|l|}{ Experimental conditions used } \\
\hline Gelatin content (\%wt) & & 17.96 & 79.34 \\
\hline TGase concentration (U/g) & & 35.65 & 6.43 \\
\hline $\mathrm{CaCl}_{2}$ contact time (min) & & 33.31 & 86.41 \\
\hline \multicolumn{4}{|l|}{ Responses } \\
\hline \multirow[t]{2}{*}{ Water content $\left(\mathrm{Y}_{1}, \% \mathrm{wt}\right)$} & Predicted & $960.38<1200.00<1439.63$ & $1660.25<1899.92<2139.59$ \\
\hline & Experimental & 1248.53 & 1931.74 \\
\hline \multirow[t]{2}{*}{ Swelling degree at $\mathrm{pH} 3\left(\mathrm{Y}_{2}, \% \mathrm{wt}\right)$} & Predicted & $57.36<64.62<71.89$ & $78.36<86.00<93.64$ \\
\hline & Experimental & 66.72 & 76.57 \\
\hline \multirow[t]{2}{*}{ Swelling degree at $\mathrm{pH} 7\left(\mathrm{Y}_{3}, \% \mathrm{wt}\right)$} & Predicted & $48.64<60.47<72.29$ & $72.94<85.79<98.64$ \\
\hline & Experimental & 57.22 & 77.27 \\
\hline
\end{tabular}

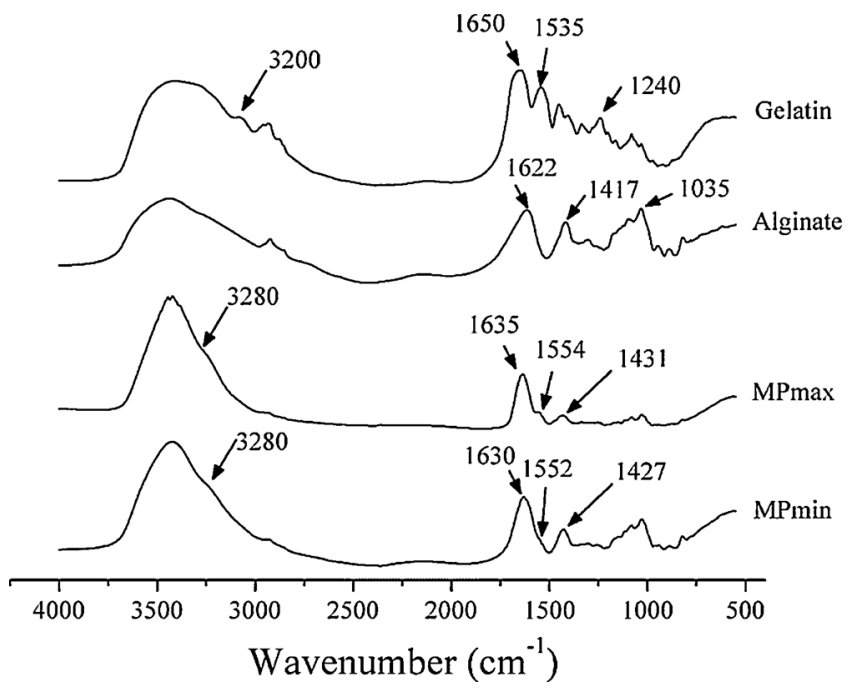

Fig. 4. FTIR spectra of gelatin, alginate and the produced microparticles produced under the validated conditions of maximized responses $\left(\mathrm{MP}_{\max }\right)$ and minimized responses $\left(\mathrm{MP}_{\min }\right)$.
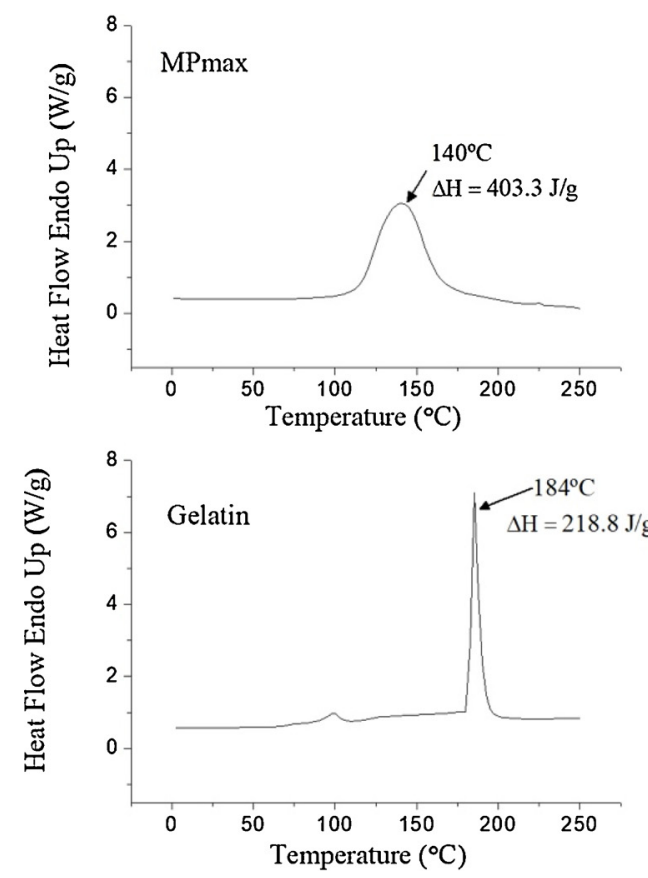

$\mathrm{MP}_{\text {max }}$, all the other defined responses where experimentally validated, since experimental results were within the confidence interval. This demonstrates the good predictive capability of the models.

The obtained FTIR and DSC results for MPmax and MPmin samples (two boundary conditions) also enable to confirm the occurrence of the crosslinking reaction of gelatin induced by TGase and the one of alginate through $\mathrm{Ca}^{2+}$ ions. In the FTIR spectra of gelatin the characteristic absorption bands of amide $\mathrm{A}$ band $(\mathrm{N}-\mathrm{H}$ stretching), amide $\mathrm{I}(\mathrm{C}=\mathrm{O}$ stretching vibration), amide II (C-N stretching vibration combined with $\mathrm{N}-\mathrm{H}$ bending) and of amide III (amide $\mathrm{C}-\mathrm{N}$ and $\mathrm{N}-\mathrm{H}$ and glycine $\mathrm{C}-\mathrm{H}_{2}$ ) may be observed at 3200, 1650, 1535 and $1240 \mathrm{~cm}^{-1}$, respectively (Bergo \& Sobral, 2007; Chang \& Tanaka, 2002). The iso-peptide bonds formed during the crosslinking promoted by TGase increases the number of bounded $\mathrm{N}-\mathrm{H}$ groups (Liu et al., 2016), thus intensifying the amide A and amide I bands, which can be noted in the spectra of both microsphere samples ( $\mathrm{MP}_{\min }$ and $\mathrm{MP}_{\max }$ ). This intensity increase of the amide I peak was previously observed by Veiga et al. (2016) and Liu et al. (2016). A displacement of this band from $3200 \mathrm{~cm}^{-1}$ to $3280 \mathrm{~cm}^{-1}$ was also found, as well as the displacement of the amide II band from 1535 to 1552 and $1554 \mathrm{~cm}^{-1}$ for MPmin and MPmax samples, respectively. For alginate sample, it is possible to observe the characteristic bands located at $1622 \mathrm{~cm}^{-1}\left(\mathrm{COO}^{-}\right.$stretching), at
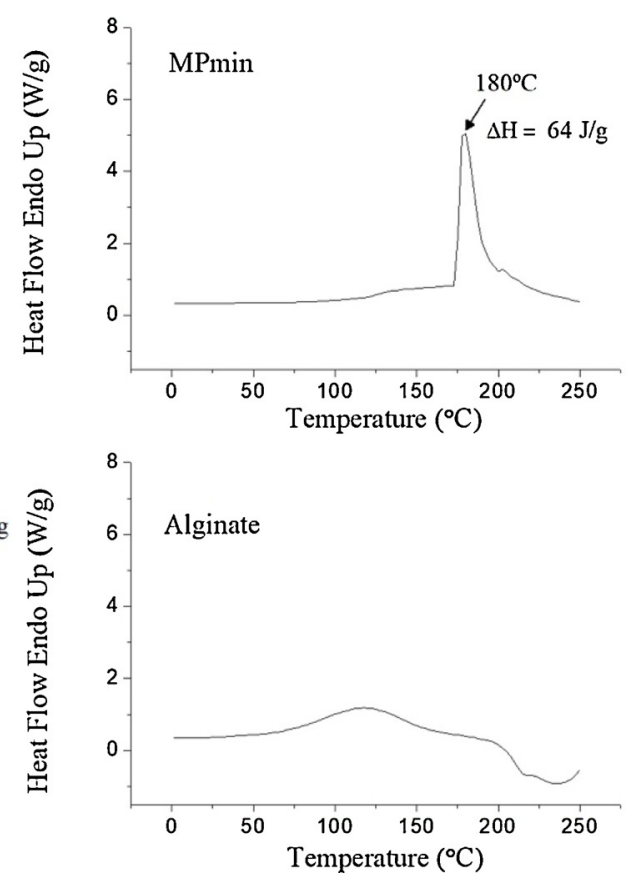

Fig. 5. DSC thermograms of gelatin, alginate and the microspheres produced under the validated conditions $\left(\mathrm{MP}_{\max }\right.$ and $\left.\mathrm{MP}_{\min }\right)$ putting in evidence the maximum peak temperature and the respective enthalpy values. 
$1417 \mathrm{~cm}^{-1}$ (overlapping of symmetric COO- stretching and $\mathrm{OH}$ bending), at $1035 \mathrm{~cm}^{-1}$ (C-O-C stretching). In the microspheres spectra the band related to the COO- stretching presented a shift to 1431 and $1427 \mathrm{~cm}^{-1}$ for MPmin and MPmax samples, respectively, which is an indicative of the association of this group with the $\mathrm{Ca}^{+2}$ during alginate crosslinking (Costa et al., 2018).

Considering DSC analysis, alginate thermogram presented a large peak with a low heat flow associated, probably due to moisture evaporation, while gelatin sample present an endothermic peak located at $184^{\circ} \mathrm{C}$. In the case of $\mathrm{MP}_{\max }$ sample, the peak presented a displacement to lower temperatures and a higher transition energy. In the case of $\mathrm{MP}_{\min }$ sample, the peak location is similar to the one of pure gelatin, but a lower enthalpy variation was found comparatively to gelatin. These displacements can be associated with a plasticizing effect of alginate in the gelatin tridimensional structure. This effect is more pronounced in $\mathrm{MP}_{\max }$, where alginate is the minor compound in the matrix, being dispersed into the other compound, gelatin. On the other hand, for $\mathrm{MP}_{\min }$ the effect is reduced, fact justified by a predominant presence of alginate, hindering its role as plasticizer and thus preserving gelatin thermal behavior. Furthermore, the increase in the energy variation associated to the thermal transition, observed for the sample $\mathrm{MP}_{\max }$, can be related with the effect of crosslinking.

\section{Conclusion}

A process for the production of microparticles composed by transglutaminase-crosslinked gelatin and calcium chloride-crosslinked alginate was carried out by using a central composite rotatable experimental design. The influence of gelatin concentration in the polymeric mixture, transglutaminase and contact time of the droplets with the calcium chloride on the water content of the particles after production, and the swelling degree at $\mathrm{pH} 3$ and $\mathrm{pH} 7$ was evaluated. The particles microstructure was greatly affected by the gelatin content and the transglutaminase concentration. The most important factor to determine the swelling degree was the gelatin content, considering the range of the evaluated experimental parameters. In general, results indicated that an increase in gelatin concentration led to the achievement of particles with a higher water content. Moreover, the isoelectric point of gelatin influenced the swelling degree of the particles at the tested pHs ( 3 and 7). Multiobjective optimization was used to validate two experimental points in which the responses were simultaneously maximized or minimized, showing the good predictive capability of the developed models. The produced microparticles have the potential to be used as carriers for bioactive substances in the formulation of freeze dried nutraceutical foodstuffs.

\section{Acknowledgments}

This work was financially supported by Associate Laboratory LSRELCM (UID/EQU/50020/2019) funded by national funds through FCT/ MCTES (PIDDAC), and Foundation for Science and Technology (FCT, Portugal) and by CIMO (UID/AGR/00690/2019) trough FEDER under Program PT2020. The authors are grateful to CAPES, CNPq and Fundação Araucária for the support and also to Ajinomoto Foods Europe S.A.S. (France) for kindly provide the transglutaminase sample used in this work. I.P. Fernandes thanks the national funding by FCT, P.I., through the institutional scientific employment program-contract for her contract.

\section{References}

Aspen Medical Europe (2016). Sorbsan.

Bergo, P., \& Sobral, P. J. A. (2007). Effects of plasticizer on physical properties of pigskin gelatin films. Food Hydrocolloids, 21, 1285-1289. https://doi.org/10.1016/j.foodhyd. 2006.09.014.

Boeing, J. S., Barizão, É. O., e Silva, B. C., Montanher, P. F., de Cinque Almeida, V., \& Visentainer, J. V. (2014). Evaluation of solvent effect on the extraction of phenolic compounds and antioxidant capacities from the berries: Application of principal component analysis. Chemistry Central Journal, 8, 48. https://doi.org/10.1186/ s13065-014-0048-1.

Bona, E., Borsato, D., Sérgio dos Santos Ferreira, R., \& Paula Herrera, R. (2000). Aplicativo para otimização empregando o método simplex seqüencial. Acta Science Technologies, 22, 1201-1206.

Caló, E., \& Khutoryanskiy, V. V. (2015). Biomedical applications of hydrogels: A review of patents and commercial products. European Polymer Journal, 65, 252-267. https:// doi.org/10.1016/j.eurpolymj.2014.11.024.

Castro, I. A., Silva, R. S. F., Tirapegui, J., Borsato, D., \& Bona, E. (2003). Simultaneous optimization of response variables in protein mixture formulation: Constrained simplex method approach. International Journal of Food Science \& Technology, 38, 103-110. https://doi.org/10.1046/j.1365-2621.2003.00650.x.

Chang, M. C., \& Tanaka, J. (2002). FT-IR study for hydroxyapatite/collagen nanocomposite cross-linked by glutaraldehyde. Biomaterials, 23, 4811-4818. https://doi. org /10.1016/S0142-9612(02)00232-6.

Costa, M. J., Marques, A. M., Pastrana, L. M., Teixeira, J. A., Sillankorva, S. M., \& Cerqueira, M. A. (2018). Physicochemical properties of alginate-based films: Effect of ionic crosslinking and mannuronic and guluronic acid ratio. Food Hydrocolloids, 81, 442-448. https://doi.org/10.1016/j.foodhyd.2018.03.014.

Food Ingredients Brasil (2013). Os alginatos e suas múltiplas aplicações. Food Ingredients Brasil.

Food Ingredients Brasil (2010). Estabilizantes. Food Ingredients Brasil.

Fuchs, R. H. B., Ribeiro, R. P., Bona, E., \& Matsushita, M. (2013). Development of a freezedried mixture of Nile tilapia (Oreochromis niloticus) croquette using a GA-based multiobjective optimisation. Journal of the Science of Food and Agriculture, 93, 1042-1048. https://doi.org/10.1002/jsfa.5844.

Gabriel, A. A. (2008). Estimation of water activity from $\mathrm{pH}$ and ${ }^{\circ}$ Brix values of some food products. Food Chemistry, 108, 1106-1113. https://doi.org/10.1016/j.foodchem. 2007.11.077.

Gao, F., \& Han, L. (2012). Implementing the Nelder-Mead simplex algorithm with adaptive parameters. Computational Optimization and Applications, 51, 259-277. https://doi.org/10.1007/s10589-010-9329-3.

George, M., \& Abraham, T. E. (2007). pH sensitive alginate-guar gum hydrogel for the controlled delivery of protein drugs. International Journal of Pharmaceutics, 335, 123-129. https://doi.org/10.1016/j.ijpharm.2006.11.009.

Gharibzahedi, S. T. M., Koubaa, M., Barba, F. J., Greiner, R., George, S., \& Roohinejad, S. (2018). Recent advances in the application of microbial transglutaminase crosslinking in cheese and ice cream products: A review. International Journal of Biological Macromolecules, 107, 2364-2374. https://doi.org/10.1016/j.ijbiomac.2017.10.115.

Gonçalves, V. S. S., Gurikov, P., Poejo, J., Matias, A. A., Heinrich, S., Duarte, C. M. M., et al. (2016). Alginate-based hybrid aerogel microparticles for mucosal drug delivery. European Journal of Pharmaceutics and Biopharmaceutics, 107, 160-170. https://doi. org/10.1016/j.ejpb.2016.07.003.

Guo, Y.-H., Zhao, S., Du, Y.-X., Xing, Q.-J., Chen, B.-L., \& Yu, C.-Q. (2017). Effects of ginsenoside Rg1-loaded alginate-chitosan microspheres on human bone marrow stromal cells. Bioscience Reports, 37, BSR20160566. https://doi.org/10.1042/ BSR20160566.

Ha, H., Nam, G., Khang, D., \& Park, S. J. (2017). Development of two-step temperature process to modulate the physicochemical properties of $\beta$-lac- toglobulin nanoparticles. Food Science Animal Resource, 37, 123-133.

İnal, M., Işıklan, N., \& Yiğitoğlu, M. (2017). Preparation and characterization of pHsensitive alginate-g-poly(N-vinyl-2-pyrrolidone)/gelatin blend beads. Journal of Industrial and Engineering Chemistry, 52, 128-137. https://doi.org/10.1016/j.jiec. 2017.03.034.

Jin, M., \& Zhong, Q. (2013). Transglutaminase cross-linking to enhance elastic properties of soy protein hydrogels with intercalated montmorillonite nanoclay. Journal of Food Engineering, 115, 33-40. https://doi.org/10.1016/j.jfoodeng.2012.09.016.

Kawaguti, H. Y., Carvalho, P. H., Figueira, J. A., \& Sato, H. H. (2011). Immobilization of Erwinia sp. D12 cells in Alginate-Gelatin Matrix and conversion of sucrose into isomaltulose using response surface methodology. Enzyme Research. https://doi.org/10. 4061/2011/791269.

Liu, F., Chiou, B., Avena-bustillos, R. J., Zhang, Y., Li, Y., Mchugh, T. H., et al. (2016). Food Hydrocolloids Study of combined effects of glycerol and transglutaminase on properties of gelatin fi lms. Food Hydrocolloids, 1-9. https://doi.org/10.1016/j. foodhyd.2016.10.004.

Lopes, S., Bueno, L., Júnior, A., de, F., \& Finkler, C. (2017). Preparation and characterization of alginate and gelatin microcapsules containing Lactobacillus rhamnosus. Anais Da Academia Brasileira de Ciencias, 89, 1601-1613. https://doi.org/10.1590/ 0001-3765201720170071.

Lotfipour, F., Mirzaeei, S., \& Maghsoodi, M. (2012). Evaluation of the effect of cacl2 and alginate concentrations and hardening time on the characteristics of Lactobacillus acidophilus loaded alginate beads using response surface analysis. Advanced Pharmaceutical Bulletin, 2, 71-78. https://doi.org/10.5681/apb.2012.010.

Mokarram, R. R., Mortazavi, S. A., Najafi, M. B. H., \& Shahidi, F. (2009). The influence of multi stage alginate coating on survivability of potential probiotic bacteria in simulated gastric and intestinal juice. Food Research International, 42, 1040-1045. https:// doi.org/10.1016/j.foodres.2009.04.023.

Németh, B., Németh, Á. S., Ujhidy, A., Tóth, J., Trif, L., Gyenis, J., et al. (2018). Fully biooriginated latent heat storing calcium alginate microcapsules with high coconut oil loading. Solar Energy, 170, 314-322. https://doi.org/10.1016/j.solener.2018.05.066.

Pasparakis, G., \& Bouropoulos, N. (2006). Swelling studies and in vitro release of verapamil from calcium alginate and calcium alginate-chitosan beads. International Journal of Pharmaceutics, 323, 34-42. https://doi.org/10.1016/j.ijpharm.2006.05. 054.

Roy, A., Bajpai, J., \& Bajpai, A. K. (2009). Development of calcium alginate -gelatin based 
microspheres for controlled release of endosulfan as a model pesticide. Indian Jounal of Chemical Technology, 16, 388-395.

Santhi, D., Kalaikannan, A., Malairaj, P., \& Arun Prabhu, S. (2017). Application of microbial transglutaminase in meat foods: A review. Critical Reviews in Food Science and Nutrition, 57, 2071-2076. https://doi.org/10.1080/10408398.2014.945990.

Simoni, R. C., Lemes, G. F., Fialho, S., Gonçalves, O. H., Gozzo, A. M., Chiaradia, V., et al. (2017). Effect of drying method on mechanical, thermal and water absorption properties of enzymatically crosslinked gelatin hydrogels. Anais Da Academia
Brasileira de Ciencias, 89. https://doi.org/10.1590/0001-3765201720160241. Veiga, C. C., Simoni, R. C., De Almeida, M. M. C., Gonçalves, O. H., Shirai, M. A., \& Leimann, F. V. (2016). Microencapsulation of roasted coffee oil by complex coacervation with Gelatin/Gum arabic enzymatically crosslinked. Brazilian J. Food Res. -REBRAPA, 7, 156-172.

Voron'ko, N. G., Derkach, S. R., Kuchina, Y. A., \& Sokolan, N. I. (2016). The chitosangelatin (bio)polyelectrolyte complexes formation in an acidic medium. Carbohydrate Polymers, 138, 265-272. https://doi.org/10.1016/j.carbpol.2015.11.059. 